\title{
Right Sided Acute Uncomplicated Diverticulitis: A 10 Year Retrospective Review of an Asian Cohort
}

\author{
Nan Zun Teo, Ramesh Wijaya
}

Corresponding author:

Nan Zun Teo

Associate Consultant

Department of General Surgery

Changi General Hospital

2 Simei Street 3, Singapore 529889

E-mail: teo.nan.zun@singhealth.com.sg
Department of General Surgery, Changi General Hospital, Singapore

\section{ABSTRACT}

Background: There are no well-established guidelines for treating right sided uncomplicated diverticulitis (RD). Understanding the natural history of RD may help us determine the most appropriate treatment strategy.

Method: We performed a retrospective cohort study of 402 patients admitted to our institution with Computed Tomography scan proven acute uncomplicated diverticulitis between January 2004 and December 2013. We compared patient demographics, duration and type of antibiotics, length of stay and rates of complication, recurrence and surgical intervention between right and left sided uncomplicated diverticulitis (LD).

Results: We identified 294 (73.1\%) RD and 108 (26.9\%) LD. The mean age for RD was younger (48.6 vs 61.0, $p<0.001$ ). RD received a significantly shorter mean duration of intravenous antibiotics ( 2.75 days vs 3.28 days, $p=0.01$ ) and required a significantly shorterlength of stay ( 3.35 days vs 3.94 days, $p=0.03$ ). Over a median follow-up period of 76 months the rate of complicated recurrence and surgical intervention was lower in the RD arm (0\% vs $2.78 \%, p=0.02)$

Discussion: RD occurs in a younger population with less co-morbidities, has a milder clinical course and is less likely to develop inpatient complications, complicated recurrences and to require surgical intervention. Conservative and expectant management is effective in the treatment of RD.

Key words: uncomplicated diverticulitis, right sided diverticulitis

\section{INTRODUCTION}

Diverticulosis of the colon is a common condition in Western countries affecting about a third of the population aged above 45 and up to two thirds of the population 85 and above (1). Diverticulitis is the most common complication and between 10 - 25 percent of these patients develop diverticulitis in their lifetime (2). Patients with acute uncomplicated diverticulitis (AUD) are defined as those without abscess, free air, fistula or stricture (3). The incidence of right colonic diverticulitis is low in Western countries, but is significantly higher in Asian countries, ranging from $55 \%$ - $70 \%$ (4-7).

The natural history and outcomes of acute uncomplicated left sided 
diverticulitis (LD) is well studied with numerous practice parameters describing evidenced based management protocols $(3,8)$. The current evidence suggests that LD is largely a self-limiting condition that can be managed non surgically, and recent prospective studies have shown that non-antibiotic treatment is safe and effective $(9,10)$.

Despite the high burden of disease in the East, there is few, if not contradicting literature on the natural history and management outcomes of acute uncomplicated right sided diverticulitis (RD). Many retrospective studies recommend conservative management (11-13) whereas others adopt a more aggressive operative approach (14). This is largely due to the lack of comparative studies between right and left sided diverticulitis.

The aim of this study was to retrospectively compare patient profiles, standardized objective clinical presentation parameters, treatment variables and rates of complication, recurrence and surgical intervention between RD and LD and to determine if conservative and expectant management is safe in RD.

\section{METHOD}

\section{Study Population}

We identified patients who presented to our centre with a first episode of diverticulitis over a 10-year period between January 2004 to December 2013 and retrospectively reviewed their medical records. We only included patients who had their diagnosis of uncomplicated diverticulitis verified by Computed Tomography (CT) scan and excluded all patients who were below 18 and if the attack is recurrent or complicated. Complicated diverticulitis was defined as patients with evidence of perforation, abscess, fistula or stricture formation (3). Patients in whom previous medical records were not located were also excluded from the study to maintain integrity of data collection. This study was approved by our institution's centralized institutional review board.

\section{Treatment of AUD}

All patients were treated inpatient and received antibiotics. Patients in both groups received combination therapy with ceftriaxone and metronidazole if they had no drug allergies. Patients with allergy to ceftriaxone were treated with ciprofloxacin and/or metronidazole. The attending surgeon would decide on bowel rest and route of antibiotics based on the severity of presentation, taking into account clinical and biochemical parameters. The decision for escalation of diet and discharge was also made by the attending surgeon based on response to treatment, with clinical improvement in pain, resolution of fever and biochemical improvement in white cell counts taken as surrogates of recovery. On discharge, all patients were followed-up at the specialist outpatient clinic and advised for colonic evaluation in $6-8$ weeks with colonoscopy, barium enema or CT colonography if none of these were done within a year before admission. Patients were thereafter followed up on outpatient basis at regular 3-6 monthly intervals for a year.

\section{Data collection}

The hospital medical records were retrieved, and a review of the national electronic medical records database was performed to ascertain the last follow-up visit. Clinical and biochemical parameters were captured and these include: age, gender, race, comorbidities, temperature, heart rate and white cell count on arrival, location of diverticulitis, route and duration of antibiotics, length of bowel rest, length of stay and rates of complication, recurrence and surgical intervention. RD was defined as any disease occurring in the large bowel from the ascending colon to the splenic flexure, and LD was defined as any disease occurring from the descending colon to the sigmoid colon. Complication was defined as bowel perforation with free air, abscess, fistula or septic shock requiring escalation of care after initiation of conservative treatment with antibiotics and diet modification. Recurrence was defined as a new episode of diverticulitis occurring more than 30 days after the index episode at the same site, either diagnosed clinically or on CT imaging.

\section{Statistical Analysis}

Categorical variables were analysed using the chisquared test or Fisher's exact test where appropriate. Continuous variables were analysed using the MannWhitney U-test or Student's t-test where appropriate. All data analysis was performed using the SPSS software package version 22.0 (SPSS, Chicago, Illinois, USA) and $p$ values $<0.05$ were considered to be statistically significant. 


\section{RESULTS}

\section{Patient Characteristics}

402 patients fulfilled our inclusion criteria and formed the study population. See fig. 1. There were 294 (73.1\%) RD and 108 (26.9\%) LD. The RD group had a

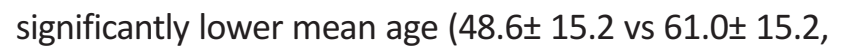
$\mathrm{p}<0.001$ ) and had lower rates of co-morbidities of Hypertension (30.6\% vs $52.8 \%, p<0.001$ ), Diabetes Mellitus (12.6\% vs $24.1 \%, p=0.008)$, Hyperlipidemia (17.3\% vs $30.6 \%, p=0.005)$ and Ischaemic Heart Disease $(6.1 \%$ vs $13.0 \%, p=0.04)$. Demographic data for these 2 groups is presented in table 1 .

\section{Clinical Parameters at Presentation}

The clinical parameters at presentation are shown in table 1. There were no differences in temperature, heart rate and white cell count at presentation between the 2 groups.

\section{Treatment}

Treatment received by both groups of patients is summarized in table 2. The proportion of patients receiving intravenous antibiotics was the same in both groups. RD received a significantly shorter mean duration of intravenous antibiotics $(2.75 \pm 1.41$ vs $3.28 \pm$ 2.05 days, $p=0.01$ ). Duration of bowel rest was the same in both groups.

\section{Complications, Mortality and Recurrence}

Table 3 summarizes the eventual outcome of both groups. RD required a significantly shorter LOS (3.35 \pm 2.67 vs $3.94 \pm 2.36$ days, $p=0.03$ ). $R D$ also had a lower disease specific morbidity although this was not statistically significant $(0.34 \%$ vs $1.85 \%, p=0.18)$. All the complications were septic shock from diverticulitis, requiring escalation of care to the high dependency ward and the use of vasoactive agents. None developed free perforation or abscess requiring invasive interven-

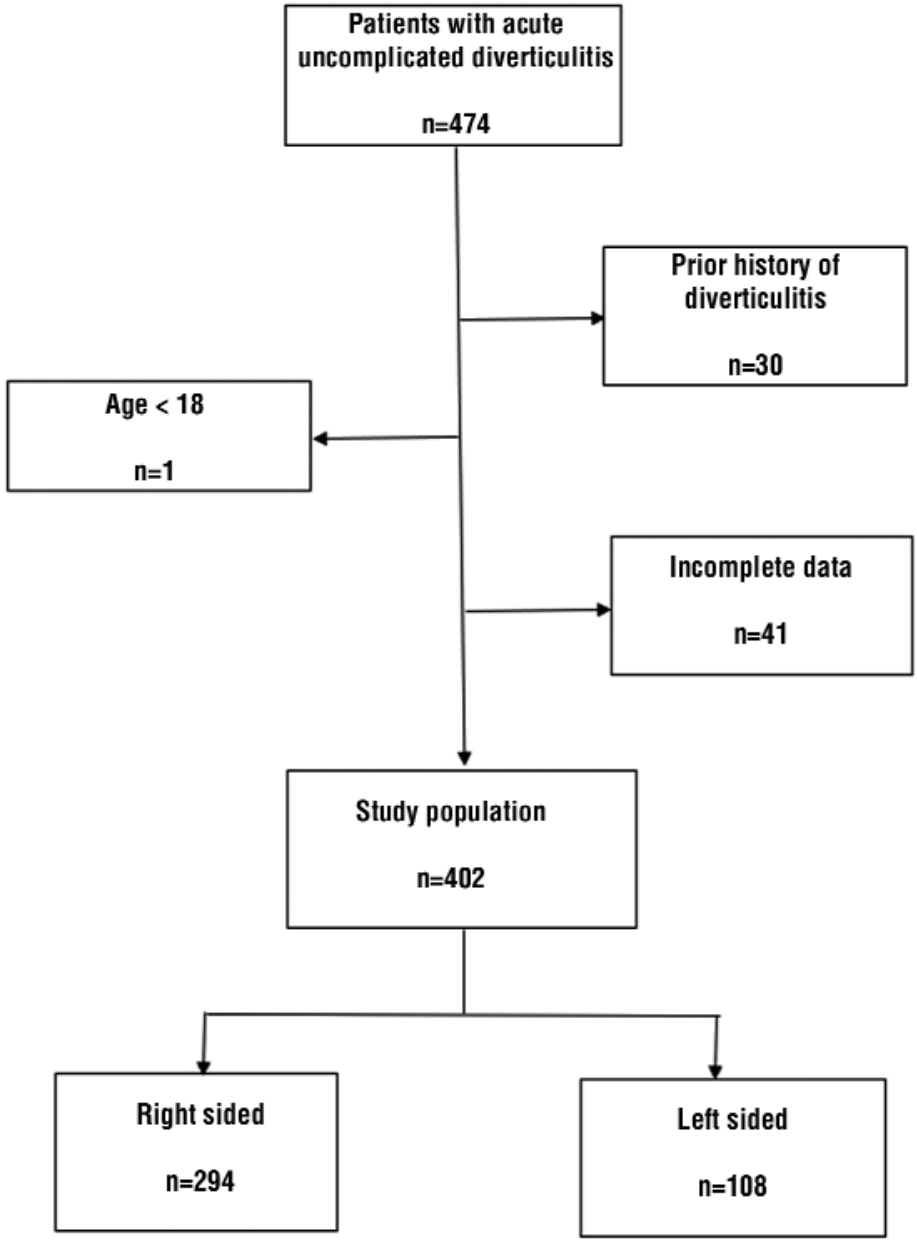


Table 1 - Patient characteristics

\begin{tabular}{|c|c|c|c|}
\hline Characteristic & $\begin{array}{c}\text { RD } \\
(n=294)\end{array}$ & $\begin{array}{c}\text { LD } \\
(n=108)\end{array}$ & $p$ value \\
\hline Age, year & $48.6 \pm 15.2$ & $61.0 \pm 15.2$ & $<0.001$ \\
\hline $\begin{array}{l}\text { Gender } \\
\text { - Male } \\
\text { - Female }\end{array}$ & $\begin{array}{l}154(52.4) \\
140(47.6)\end{array}$ & $\begin{array}{l}56(51.9) \\
52(48.1)\end{array}$ & 1.00 \\
\hline $\begin{array}{l}\text { Co-morbidities } \\
\text { - Hypertension } \\
\text { - Diabetes Mellitus } \\
\text { - Hyperlipidemia } \\
\text { - Ischaemic Heart Disease }\end{array}$ & $\begin{array}{l}90(30.6) \\
37(12.6) \\
51(17.3) \\
18(6.1)\end{array}$ & $\begin{array}{l}57(52.8) \\
26(24.1) \\
33(30.6) \\
14(13.0)\end{array}$ & $\begin{array}{c}<0.001 \\
0.008 \\
0.005 \\
0.04\end{array}$ \\
\hline $\begin{array}{l}\text { Variables at presentation } \\
\text { - Temperature (degcelcius) }{ }^{\dagger} \\
\text { - Heart rate (bpm) } \\
\text { - White cell count } \times 10^{\dagger} / \mathrm{L}^{\dagger}\end{array}$ & $\begin{array}{c}37.4 \pm 0.7 \\
88.7 \pm 14.0 \\
12.8 \pm 3.8\end{array}$ & $\begin{array}{c}37.4 \pm 0.9 \\
88.5 \pm 16.3 \\
12.7 \pm 4.4\end{array}$ & $\begin{array}{l}0.91 \\
0.92 \\
0.86\end{array}$ \\
\hline
\end{tabular}

Data is presented as mean \pm standard deviation or number $(\%)$.

${ }^{\dagger}$ Temperature, heart rate and white cell count were measured on admission.

Table 2 - Treatment characteristics in relation to site

\begin{tabular}{|c|c|c|c|}
\hline Characteristic & $\begin{array}{c}\text { RD } \\
(n=294)\end{array}$ & $\begin{array}{c}\text { LD } \\
(n=108)\end{array}$ & $\mathrm{p}$ value \\
\hline $\begin{array}{l}\text { Route of antibiotics on admission } \\
- \text { Intravenous } \\
\text { - Oral }\end{array}$ & $\begin{array}{c}285(96.9) \\
9(3.1)\end{array}$ & $\begin{array}{c}106(98.1) \\
2(1.9)\end{array}$ & 0.73 \\
\hline $\begin{array}{l}\text { Duration of antibiotics } \\
\text { - Intravenous } \\
\text { - Oral } \\
\text { - Total }\end{array}$ & $\begin{array}{c}2.75 \pm 1.41 \\
8.24 \pm 3.12 \\
10.99 \pm 3.31\end{array}$ & $\begin{array}{c}3.28 \pm 2.05 \\
8.44 \pm 3.58 \\
11.71 \pm 4.32\end{array}$ & $\begin{array}{l}0.01 \\
0.62 \\
0.12\end{array}$ \\
\hline $\begin{array}{c}\text { Duration of bowel rest } \\
\text { - Time to feeds }\end{array}$ & $1.67 \pm 1.07$ & $1.63 \pm 1.15$ & 0.73 \\
\hline
\end{tabular}

Route of antibiotics is presented as number (\%). Duration of antibiotics and bowel rest is represented as mean \pm standard deviation

Table 3 - Outcome in relation to site

\begin{tabular}{lcccc}
\hline Outcome & $\begin{array}{c}\text { RD } \\
(\mathbf{n = 2 9 4 )}\end{array}$ & $\begin{array}{c}\text { LD } \\
(\mathbf{n = 1 0 8 )}\end{array}$ & OR (95\% CI) & p value \\
\hline LOS & $3.35 \pm 2.67$ & $3.94 \pm 2.36$ & \\
\hline Septic shock & $1(0.34)$ & $2(1.85)$ & $0.181(0.016-2.015)$ & 0.18 \\
\hline Mortality & $0(0)$ & $1(0.93)$ & $\mathrm{NA}$ & 0.27 \\
\hline All recurrence & $14(4.76)$ & $8(7.41)$ & $0.625(0.255-1.534)$ & 0.33 \\
\hline $\begin{array}{l}\text { Complicated recurrence } \\
\text { and surgical intervention }\end{array}$ & $0(0)$ & $3(2.78)$ & $\mathrm{NA}$ & 0.02 \\
\hline
\end{tabular}

LOS is represented as mean \pm standard deviation. Rest of outcomes are represented as number (\%). OR, odds ratio;

$\mathrm{Cl}$, confidence interval.

tion. However, $1(0.93 \%)$ of the patients from the LD arm with septic shock eventually passed away from multi-organ failure.

Over a median follow up period of 76 months (range, 44 - 110 months), 14 (4.76\%) patients with RD and 8
(7.41\%) with LD developed a recurrence. All of the RD recurrences were uncomplicated and successfully managed conservatively. However, 3 of the 8 LD recurrences were complicated and required surgical intervention. Two recurred with perforated sigmoid 
diverticulitis that required an emergent anterior resection and the other presented with sepsis from a colo-vesical fistula and had an anterior resection and resection of fistula.

\section{DISCUSSION}

There is a high incidence of RD in Asia but no wellestablished treatment guidelines. Many of the practice parameters and management guidelines are published by the West where the majority of diverticulitis is LD. These guidelines advocate a non-operative treatment regime including antibiotics and diet modification $(3,8)$. There are however no evidence based guidelines for the treatment of RD due to the lack of comparative studies. Understanding the natural history of RD may help us determine the most appropriate treatment strategy for this disease.

Of the available literature on right sided diverticulitis, many have included both uncomplicated and complicated diverticulitis in their analysis (11,13-15) which are two distinctly different spectrums of the disease with different natural history and are guided by separate management principles $(3,8)$. The inclusion of complicated disease in these studies may have contributed to the higher proportion of reported surgical intervention and recurrence.

Some authors have advocated an aggressive approach to right sided diverticulitis to avoid the possibility of recurrent attack (14-16). For example, Fang et al recommends aggressive resection for patients with caecal diverticulitis as less than $40 \%$ (35 of 85 ) of patients were successfully treated with conservative methods (14). Others recommend a non-operative approach to RD. Matsushima et al reported successful conservative management of all 100 patients with a diagnosis of right sided diverticulitis with a low recurrence rate of $8 \%$ (11). Park et al described 276 patients with RD successfully managed by initial conservative treatment and a low recurrence rate of $1 \%$ (12). Ha et al recently described a low recurrence rate of $9.9 \%$ of 152 patients with right sided diverticulitis managed conservatively and thus concluded that conservative management is effective in right colonic diverticulitis (13). In our study, all 294 patients with RD were successfully managed conservatively with a low rate of disease specific morbidity of $0.3 \%$ and a low rate of recurrence of $4.8 \%$.

These existing studies however do not have strict inclusion criteria to only include patients with CT proven diverticulitis $(11,12,14-16)$ when it has been shown that CT has excellent sensitivity (98\%) and specificity $(99 \%),(17,18)$ and has been recommended as the standard tool in the diagnosis of diverticulitis (8). This is especially important in the Asian population with a higher incidence of patients with RD as the presentation of these patients can mimic acute appendicitis. For example, Tan et al has reported that $22.1 \%$ of patients with right sided diverticulitis were initially misdiagnosed with acute appendicitis (19). The high rate of misdiagnosis of acute appendicitis without a CT scan has resulted in a high operative rate and possibly overtreatment for RD in these studies $(11,14,19)$. As such it would be difficult to ascertain management guidelines based on them.

Furthermore, some of the existing literature have included both uncomplicated and complicated diverticulitis in their analysis $(11,13-15)$ which are two distinctly different spectrums of the disease guided by different management principles $(3,8)$.

Our study design has strict inclusion criteria and only enlisted patients with CT proven AUD. In this present cohort of patients with AUD, we compared the differences in presentation, clinical course and outcome between RD and LD. We found that RD occurred in younger patients and had significantly less comorbidities of hypertension, hyperlipidemia and ischemic heart disease. Although there were no significant differences in presentation in terms of mean temperature, heart rate and white cell count on arrival which were taken to be surrogates of inflammation and sepsis, the RD arm had a milder clinical course and a more benign outcome. They required significantly less days of intravenous antibiotics and a shorter length of stay. There was a low recurrence rate of $4.76 \%$ for RD. Furthermore, all the recurrences in the RD arm were uncomplicated and were again successfully managed conservatively. In contrast, the LD arm had a higher recurrence rate of $7.41 \%$ and had significantly more complicated recurrences that required emergency surgery.

Our study design is limited by its retrospective nature with inherent selection bias. Also the decision on duration of antibiotics and to discharge patients were made by the attending surgeon and not based on clear standardized protocols. Our data focused on uncomplicated diverticulitis, as such we cannot comment on the differences between right and left sided diverticulitis with complications such as perforation, abscess, fistulation or strictures.

Based on our study results, we conclude that RD occurs in a younger population with less co-morbidities and has a more benign natural history as compared to $L D$, requiring a shorter duration of antibiotics and LOS, 
and also has less recurrences of which none are complicated requiring surgery. Therefore, conservative and expectant management is an effective strategy in managing a patient with RD.

Results from the AVOD study and other more recent prospective studies have shown that antibiotic treatment neither accelerates recovery nor prevents complications or recurrence in $\operatorname{LD}(9,10)$. As such the Danish practice parameters recommend that the use of antibiotics in LD should not be routine (3). Having shown RD to be a more benign disease than LD it would be intuitive to suggest that antibiotic therapy may not be required in treating patients with RD. There are however no studies to date that evaluate this and future prospective studies are required.

\section{Disclosure}

This study did not receive any support in any form and there are no conflicts of interest.

\section{Funding}

This study did not receive any funding in any form

\section{REFERENCES}

1. Roberts P, Abel M, Rosen L, Cirocco W, Fleshman J, Leff E et al. Practice parameters for sigmoid diverticulitis. The Standards Task Force American Society of Colon and Rectal Surgeons. Dis Colon Rectum 1995

2. Parks TG, Connell AM. The outcome in 455 patients admitted for treatment of diverticular disease of the colon. $\mathrm{Br} \mathrm{J}$ Surg 1970;57:775-778

3. Andersen JC, Bundgaard L, Elbrond $\mathrm{H}$, et al. Danish national guidelines for treatment of diverticular disease. Dan Med J. 2012; 59: C4453

4. Chia JG, Wilde CC, Ngoi SS, Goh PM, Ong CL (1991) Trends of diverticular disease of the large bowel in a newly developed country.
Dis Colon Rectum 34:498-501

5. Lee YS. Diverticular disease of the large bowel in Singapore. An autopsy survey. Dis. Colon Rectum 1986;29:330-5.

6. Chan CC, Lo KK, Chung EC, Lo SS, Hon TY. Colonic diverticulosis in Hong Kong: distribution pattern and clinical significance. Clin. Radiol.1998;53:842-4

7. Manabe N, Haruma K, Nakajima A, Yamada M, Maruyama Y, Gushimiyagi M, Yamamoto T. Characteristics of Colonic Diverticulitis and Factors Associated With Complications: A Japanese Multicenter, Retrospective, Cross-Sectional Study. Dis. Colon Rectum 2015:58(12):1174-81

8. Feingold D, Steele SR, Lee S, Kaiser A, Boushey R, Buie WD, Rafferty JF. Practice parameters for the treatment of sigmoid diverticulitis. Dis Colon Rectum. 2014;3:284-94

9. Chabok A, Pțhlman L, Hjern F, Haapaniemi S, Smedh K; AVOD Study Group. Randomized clinical trial of antibiotics in acute uncomplicated diverticulitis. Br J Surg. 2012;99:532-539

10. Mali JP, Mentula PJ, Leppäniemi AK, Sallinen VJ; Symptomatic Treatment for Uncomplicated Acute Diverticulitis: A Prospective Cohort Study. Dis Colon Rectum. 2016;59:529-34

11. Matsushima K. Management of right-sided diverticulitis: a retrospective review from a hospital in Japan. Surg Today 2010; 40:321-5

12. Park HC, Chang MY, Lee BH. Nonoperative management of right colonic diverticulitis using radiologic evaluation. Colorectal Dis. 2008:12:105-8

13. Ha GW, Lee MR, Kim JH. Efficacy of conservative management in patients with right colonic diverticulitis. ANZ J Surg. 2015

14. Fang JF, Chen RJ, Lin BC, Hsu YB, Kao JL, Chen MF. Aggressive resection is indicated for cecal diverticulitis. Am. J. Surg. 2003:185:135-40

15. Lane JS, Sarkar R, Schmit PJ, Chandler CF, Thompson JE Jr. Surgical approach to cecal diverticulitis. J. Am. Coll. Surg. 1999;188:629-34

16. Papaziogas B, Makris J, Koutelidakis I et al. Surgical management of cecal diverticulitis: is diverticulectomy enough? Int. J. Colorectal Dis.2005;20:24-7

17. Laméris $W$, van Randen $A$, Bossuyt PMM, et al. Graded compression ultrasonography and computed tomography in acute colonic diverticulitis: meta-analysis of test accuracy. Eur Radiol. 2008;18: 2498-2511

18. Ambrosetti P, Jenny A, Becker C, Terrier TF, Morel P. Acute leftcolonic diverticulitis-compared performance of computed tomography and water-soluble contrast enema: prospective evaluation of 420 patients. Dis Colon Rectum. 2000;43: 1363-1367

19. Tan KK, Wong J, Sim R. Non-operative treatment of right-sided colonic diverticulitis has good long-term outcome: a review of 226 patients. Int J Colorectal Dis 2012;6:849-54 